\title{
REFLEXÕES GEOGRÁFICAS DIANTE DA PANDEMIA: RELATO DE EXPERIÊNCIA EM ENSINO REMOTO ${ }^{1}$
}

\author{
GEOGRAPHICAL REFLECTIONS BEFORE PANDEMIA: \\ REPORT OF EXPERIENCE IN REMOTE TEACHING
}

\section{Lucian Armindo da Silva Brinco ${ }^{2}$, Ana Carla Lenz ${ }^{3}$ e Natália Lampert Batista ${ }^{4}$}

\section{RESUMO}

O presente texto apresenta uma reflexão sobre os diálogos realizados na disciplina de "Tópicos Especiais de Geografia B” (GCC896), ofertada pelo Programa de Pós-graduação em Geografia (PPGGeo), da Universidade Federal de Santa Maria (UFSM). Para tanto, a abordagem utilizada foi a qualitativa, realizando um debate sobre a realização da disciplina em ensino remoto. Dessa forma, considera-se que as discussões que ocorreram ao longo da disciplina favoreceram as reflexões sobre o ensino de Geografia, em seu sentido amplo, no contexto pandêmico. Os debates foram de suma importância para a formação continuada dos profissionais da área e, também, para mudanças de cunho pessoais para estudantes e docente. Por fim, pode-se dizer que foram espaços relevantes para a construção de um ensino de Geografia mais significativo e de qualidade em época de ensino remoto.

Palavras-chave: Pandemia. Ensino Remoto. Ensino de Geografia.

\section{ABSTRACT}

This text presents a reflection on the dialogues held at a distance in the discipline of "Tópicos Especiais de Geografia B" (GCC896), offered by the Programa de Pós-graduação em Geografia (PPGGeo), from the Universidade Federal de Santa Maria (UFSM). Therefore, the qualitative approach was used, carrying out a debate and reflections on the realization of the discipline in remote education. Thus, it is considered that the discussions that occurred throughout the discipline favored the reflections on the teaching of Geography, in its broad sense, in the pandemic context. The debates were of paramount importance for the continuing education of professionals in the field and, also, for personal changes for students and teachers. Finally, it can be said that they were relevant spaces for the construction of a more meaningful and quality teaching of Geography at the time of Remote Teaching.

Keywords: Pandemic. Remote Teaching. Geography teaching.

\footnotetext{
${ }^{1}$ Relato de experiência - Universidade Federal de Santa Maria (UFSM).

${ }^{2}$ Graduado em Geografia - UFSM. E-mail: ?

${ }^{3}$ Doutoranda em Geografia - UFSM. E-mail: ?

${ }^{4}$ Orientadora. Doutora em Geografia - UFSM. E-mail: ?
} 


\section{INTRODUÇÃO}

O presente texto traz um diálogo sobre a realização da disciplina de "Tópicos Especiais de Geografia B” (GCC896), ofertada pelo Programa de Pós-graduação em Geografia (PPGGeo), da Universidade Federal de Santa Maria (UFSM). As aulas presenciais na instituição foram suspensas logo depois do primeiro encontro devido a pandemia do COVID-19, por isso a disciplina foi organizada em formato remoto, conforme apresenta Batista (2020) no Plano de aula publicado na Revista Metodologias e Aprendizados. Com a situação de excepcionalidade posta, a professora e os alunos tiveram que se adaptar, rapidamente, ao ensino remoto, buscando novas estratégias para a realização das atividades proposta.

Ressalta-se que a disciplina de tópicos é ofertada anualmente por professores convidados do PPGGeo com temáticas variadas, de acordo com a necessidade dos pós-graduandos matriculados no ano. Assim,

[...] a disciplina propõe uma reflexão teórica e prática acerca da metodologia de pesquisa relacionadas à linha de pesquisa Dinâmicas da Natureza e Qualidade Ambiental do Cone Sul e é "desenvolvida por professores convidados, para atender a demandas específicas que se coloquem dentro da linha de pesquisa" (EMENTA, 2020, p. 01). [...] O desafio apresentado por essa disciplina se refere ao fato de ser a primeira disciplina em Pós-graduação ministrada pela docente e, consequentemente, por estar justaposto a uma das maiores adversidades em saúde do século. Por outro lado, a temática que permeia e direciona a proposta foi "Formação de professores de Geografia e currículo escolar: abordagem teórico-prática", o que leva a reflexão dos contratempos presentes na constituição dos professores e na exequibilidade dos currículos. (BATISTA, 2020, p. 167).

O perfil dos estudantes matriculados era diversificado, composto por Pós-graduandos (Mestrandos e Doutorandos) e por Alunos Especiais (Graduados em Geografia e Professores das Rede Municipal e Particular de Ensino de Santa Maria, RS). Tal perfil enriqueceu os olhares frente a disciplina, potencializando as discussões sobre os diferentes dilemas que permeiam a sala de aula da Educação Básica e Superior, bem como conduzindo a todos os envolvidos a reflexão e (auto) avaliação das posturas docentes dos envolvidos nas discussões.

A estruturação desse artigo divide-se em dois eixos. No primeiro subtítulo, "Aulas remotas no contexto pandêmico", são apresentadas reflexões sobre o ensino remoto pelo olhar dos pós-graduandos matriculados na disciplina “Tópicos Especiais em Geografia B”. Na sequência, o eixo "Sobre a pauta metodologias de ensino" apresentou diálogos realizados no contexto das aulas desenvolvidas através das plataformas digitais. A abordagem utilizada foi a qualitativa. Fez-se uso da pesquisa bibliográfica e do relato de experiência como reflexão das vivências acadêmicas do primeiro semestre de 2020 . A importância do estudo e dos relatos de experiência da educação remota está nessa correlação entre experiências positivas com a adaptabilidade das metodologias de ensino neste momento excepcional de pandemia. 


\section{AULAS REMOTAS NO CONTEXTO PANDÊMICO}

Iniciamos este diálogo com a seguinte pergunta: quando a educação deixa de existir? Aquela educação com práticas de ensino voltadas para as realidades locais e impregnadas com as diversidades que configuram a escola? Segundo Hillessheim (2018), ela desaparece quando não se dialoga com o público das instituições ou quando se deixa de escutar, de se ver ou, ainda, se finge que não se vê a realidade e, também, quando não se possui caminhos e alternativas as dificuldades que se apresentam à docência.

As metas, nesse sentido, são confusas e os olhares não focam. Além do temido novo, das novas ideias, do diferente que possibilitaria construir uma nova sociedade. Desta forma, permanece-se no mesmo, não favorecendo o compartilhamento dos diversos conhecimentos existentes nas atividades extras-escolares dos múltiplos lugares do espaço geográfico do Brasil. (HILLESSHEIM, 2018, p. 13).

A crítica de Hillesheim (2018) foi direcionada à Educação do Campo, mas se analisarmos a realidade educacional brasileira, observa-se que ela pode ser direcionada para todo o "campo" educacional. Assim sendo, essas reflexões nos levam a pensar que o ensino de Geografia no contexto apresentado poderia findar, se não fossem buscadas estratégias e alternativas a realização dos debates na disciplina de "Tópicos Especiais de Geografia B".

Os encontros deveriam ter sido presenciais, na UFSM, contudo, teve-se apenas uma aula presencial. Batista (2020, p. 168) ressalta que no dia 10 de março de 2020, a disciplina foi apresentada aos pós-graduandos e realizou-se uma confraternização de boas-vindas. A segunda aula presencial, prevista para a semana seguinte, “[...] todavia, não ocorreu, pois no dia anterior a sua realização foi decretada a suspensão das atividades presenciais [...] em virtude da propagação do novo Coronavírus. Assim, o cronograma proposto necessitou ser alterado e reformulado, buscando minimamente comtemplar as dimensões centrais da proposta de disciplina".

As duas primeiras aulas após a suspensão das atividades presenciais foram, meramente, uma antecipação de atividades que já estavam previstas para serem realizadas a distância ou a organização de trabalhos que seriam apresentados. Precisava-se de definições referentes ao fluxo das aulas no formato de Regime de Exercícios Domiciliares Especiais (REDE), passou-se do planejamento às incertezas. A Plataforma da disciplina, sistematizada no Google Classroom, como apoio a disponibilização de materiais complementares para as aulas presenciais, passou a ser central na comunicação com os pós-graduandos, assim como o, então, criado Grupo no WhatsApp e as reuniões no <https://meet.jit.si/>. Assim, todo o material e orientações sobre as aulas ficavam disponíveis no Google Classroom. As dúvidas, avisos e debates breves eram realizados no Grupo no WhatsApp. E, nas terças-feiras à tarde, horário da disciplina, realizavam-se as reuniões no <https://meet.jit.si/> para debater os temas voltados as leituras, desabafar frente as incertezas que pairavam (e ainda persistem) sobre o semestre, bem como para discutir as perspectivas futuras para o ensino de Geografia, para a formação de professores e para os currículos de Geografia nos países do Cone Sul. (BATISTA, 2020, p. 168). 
Nessa perspectiva, com a suspensão das atividades presenciais, fez-se uso de ambientes virtuais como o Google Classroom, o Meet.Jit si e o WhastApp para as aulas. Os conteúdos e as atividades foram postados no Classroom e posteriormente, debatidas pelo Meet.Jit si. Todo o processo foi marcado pelo diálogo entre os pós-graduandos e a professora, buscando promover as atividades de forma a contemplar os anseios de pesquisa de todos os envolvidos, respeitando os seus tempos-espaços e as dificuldades apresentadas pela pandemia de COVID-19.

Destaca-se que o diálogo:

É uma relação horizontal de A com B. Nasce de uma matriz crítica e gera criticidade. Nutre-se do amor, da humildade, da esperança, da fé, da confiança. Por isso, só com o diálogo se ligam assim, com amor, com esperança, com fé um no outro, se fazem críticos na busca de algo. Instala-se, então, uma relação de simpatia entre ambos. Só aí há comunicação. O diálogo é, portanto, o indispensável caminho, não somente nas questões vitais para a nossa ordenação política, mas em todos os sentidos do nosso ser. Somente pela virtual da crença, contudo, tem o diálogo estímulo e significação: pela crença no homem e nas suas possibilidades, pela crença de que somente chego a ser eles mesmos". (FREIRE, 2007, p. 115-116).

A tecnologia, neste caso, foi aliada na manutenção das aulas e contribuiu com o processo de ensino e aprendizagem, além de favorecer na (auto) formação docente em nível de pós-graduação, como pode ser observado no relato dos participantes destacados no Quadro 1. É essencial pontuar, entretanto, que isso só foi possível graças ao acesso dos pós-graduandos a infraestrutura básica para acesso as aulas e realização das atividades proposta. Em outros contextos de vulnerabilidade social, talvez, a metodologia empreendida não fosse possível de ser executada.

Quadro 1 - Exemplos de relatos referentes a disciplina Tópicos Especiais em Geografia B.

\begin{tabular}{|l|l|l|}
\hline & "A disciplina Tópicos Especiais em Geografia B proporcionou, mesmo que de forma virtual, um diálogo sobre a \\
$\mathbf{R}$ & Educação no Brasil, em especial ao ensino de Geografia. Pensar o ensino de Geografia no atual contexto, possibi- \\
$\mathbf{E}$ & litou trocas de saberes, de conhecimentos, que colaboraram com a minha prática pedagógica na implementação do \\
$\mathbf{L}$ & nosino remoto. Além disso, a disciplina nos levou a estudar os documentos curriculares dos países do Cone-Sul, \\
$\mathbf{A}$ & debate outras realizadas nas quais não estamos inseridos, mas que colaboraram para uma análise/comparação com \\
$\mathbf{T}$ & a Geografia escolar brasileira. Outros aspectos relevantes que a disciplina contribuiu foram: pensar numa formação \\
$\mathbf{O}$ & $\begin{array}{l}\text { continuada para os professores, pensar práticas pedagógicas que baseiam na realidade do aluno (já eram necessá- } \\
\text { rias e no atual contexto tornam-se primordiais), a importância da Geografia na formação de cidadãos conscientes e }\end{array}$ \\
$\mathbf{1}$ & $\begin{array}{l}\text { comprometidos com a sociedade e com a natureza. Por fim, posso inferir a disciplina proporcionou melhorar minha } \\
\text { prática e trouxe novas perspectivas sobre o ensino de Geografia. Também, peço desculpas por não ter conseguido }\end{array}$ \\
& acompanhar todas as atividades da turma, devido à sobrecarga colocada aos professores da Rede Municipal de \\
& Ensino para a implementação do currículo emergencial do Ensino Remoto". \\
\hline
\end{tabular}




\begin{tabular}{|c|c|}
\hline $\begin{array}{l}\text { R } \\
\mathbf{E} \\
\mathbf{L} \\
\mathbf{A} \\
\mathrm{T} \\
\mathbf{O}\end{array}$ & $\begin{array}{l}\text { "Proporcionar espaços, mesmo que virtuais, para a dialocidade sobre a educação brasileira é importante. As interações } \\
\text { comunicativas nesses locais auxiliam para a (re)descoberta de conceitos (modos de pensar), por meio de trocas de sabe- } \\
\text { res, de conhecimentos. Outra atividade relevante foi o estudo dos documentos norteadores da Educação Escolar do Cone } \\
\text { Sul, este favoreceu a compreensão de como o ensino de Geografia está alocado nos currículos dos países que compõem o } \\
\text { núcleo. Neste contexto, se infere que a disciplina Tópicos Especiais em Geografia B não só contribuiu com a elucidação } \\
\text { da realidade do ensino Geografia no território nacional, mas também dos países vizinhos. Colaborando com as reflexões } \\
\text { sobre: a) as práticas de ensino de Geografia; b) formação do profissional da área; c) importância da Geografia para a } \\
\text { sociedade; d) o futuro da Geografia Escolar. Isso tudo enfrentando dificuldades como: isolamento social e a qualidade do } \\
\text { sinal de internet em virtude da pandemia do COVID-19. Concluo esta avaliação destacando que a disciplina, além do já } \\
\text { exposto, também, foi favorável para o melhoramento do meu currículo acadêmico". }\end{array}$ \\
\hline $\begin{array}{l}\text { R } \\
\text { E } \\
\text { L } \\
\text { A } \\
\text { T } \\
\text { O }\end{array}$ & $\begin{array}{l}\text { "A disciplina foi importante em diversos aspectos, permitiu muitas reflexões ao longo do semestre, a docente trouxe } \\
\text { bibliografias e leituras muito enriquecedoras no que tange o ensino em Geografia e suas práticas. Foi possível ama- } \\
\text { durecer o olhar acerca das práticas escolares e a realidade que os professores vêm enfrentando na atualidade. Ótimas } \\
\text { discussões levantadas durante as aulas; quero agradecer aos colegas e a professora pela dedicação e preparo. A meu } \\
\text { ver não há pontos negativos a serem destacados, entretanto senti falta de uma prática, contudo sabemos que com a } \\
\text { Pandemia não foi possível. Tirando esse detalhe, a disciplina se desenvolveu da melhor forma possível". }\end{array}$ \\
\hline $\begin{array}{l}\text { R } \\
\text { E } \\
\mathbf{L} \\
\mathbf{A} \\
\mathbf{T} \\
\mathbf{O}\end{array}$ & $\begin{array}{l}\text { "Me sinto contemplado pelas respostas das colegas. Sem dúvida, esta disciplina foi muito gratificante para mim, ou } \\
\text { melhor, para todos nós. Todos os momentos que trocamos ideias, experiências e saberes, refletimos e debatemos } \\
\text { sobre o ensino de Geografia em seu sentido mais amplo foram de suma importância para nossas formaços pessoais } \\
\text { e profissionais. São espaços como esses que se fazem relevantes e, ao mesmo tempo, tão necessários para todos nós } \\
\text { e para a construção de um ensino de Geografia que seja mais significativo e de qualidade. Na minha visão, não há } \\
\text { nenhum ponto negativo que precise ser destacado. Embora existissem algumas limitações proporcionadas pela Pan- } \\
\text { demia, conseguimos driblá-las e, consequentemente, desenvolvermos um trabalho muito enriquecedor. Ser profes- } \\
\text { sor(a) exige, entre muitas outras coisas, reinventar-se, refletir constantemente a respeito de suas práticas pedagógicas, } \\
\text { avaliar a postura que adota diante das várias adversidades encontradas na profissão, que, por sua vez, todos nós bem } \\
\text { sabemos. Desse modo, a presente disciplina foi um exemplo muito claro disso. Acredito que esse é um dos caminhos } \\
\text { que precisamos trilhar em busca da valorização da Geografia, seja como área do conhecimento ou como disciplina } \\
\text { escolar, e, por sinal, acerca dos rumos da educação em sua totalidade. Finalmente, só me resta agradecer a todos pelo } \\
\text { acolhimento. Em especial, também sou grato pela professora ter, gentilmente, me convidado para participar de uma }\end{array}$ \\
\hline
\end{tabular}
Fonte: BATISTA, 2020, p. 173.

Assim, infere-se, com o descrito pelos pós-graduandos, que a disciplina não só promoveu a elucidação do contexto da educação escolar, dos currículos e da formação docente dos países do Cone Sul, mas contribuiu com a autoformação docente e aperfeiçoamento das práticas pedagógicas de ensino remoto exigido neste período de pandemia dos próprios participantes dela. Assim, pode-se apontar que:

Pensar a relação formação de professores, ensino de Geografia e currículo escolar fomenta um olhar para além da insensatez meramente metodologia das pesquisa da área e demostra a urgência do entendimento da aula de Geografia como algo complexo, integrado e que passa por uma efetiva formação docente (inicial e continuada, pautada nas realidades das escolas), na disponibilidade de infraestruturas para a realização das práticas, nas condições socioeconômicas (dos professores e alunos) que influenciarão diretamente na aprendizagem e na interpretação e implementação dos currículos. Esses debates permearam a disciplina desenvolvida e instigaram os pós-graduandos a tecerem uma argumentação contextualizada e menos ingênua frente à escola, ao ensino de Geografia e ao que se buscará para ele no pós-pandemia. [...] Apesar do contexto de excepcionalidade, a disciplina cumpriu seus objetivos e colaborou com as discussões que se propunha, enfatizando a realidade escolar como chave a formação de professores e as práticas pedagógicas nas escolas. (BATISTA, 2020, p. 174). 
Dessa maneira, essas foram algumas das reflexões que ocorreram nos debates promovidos pela disciplina de "Tópicos Especiais em Geografia B", visando a elucidação de que a educação faz parte de algo maior do que o ensino de conteúdos específicos. Ela prepara os sujeitos para a vida em sociedade, mas, para que isso realmente ocorra, deve-se lançar o olhar para as realidades, as especificidades locais. Manter um diálogo constante com a comunidade que fornece o público para a escola, buscando, assim, ver, interpretar e problematizar o que realmente é importante ensinar, principalmente neste período em que as pessoas estão (alunos e professores, em especial) em isolamento social.

\section{SOBRE A PAUTA METODOLOGIAS DE ENSINO}

Uma das pautas das discussões da disciplina “Tópicos Especiais em Geografia B” foram as metodologias de ensino. Observou-se que, no contexto atual, há uma grande divulgação de trabalhos científicos nas plataformas digitais acerca delas, porém, nem sempre os debates acerca delas são aprofundados. Essa difusão de debates possibilita aos professores, de diferentes lugares do mundo, a troca de saberes e experiências de maneira acessível, em virtude da exposição, como, também, através desta facilidade de contato, promove a possibilidade de reforçá-las por meio de relatos de prática ou até mesmo compará-las, visando fazer uso da que melhor se enquadra no contexto em que os membros da comunidade escolar estão inseridos.

Para a escolha da melhor metodologia, o docente, geralmente, leva em consideração inúmeros fatores referentes ao contexto de sua sala de aula, como: idade dos alunos, conteúdo a ser ensinado, acesso a recursos educacionais, entre outros. Isso tudo pode ser associado as diferentes propostas difundidas nas plataformas de ensino-aprendizagem e publicações de metodologias. Porém, outra questão se pode levantar é que, embora as metodologias que envolvem o processo de ensino e aprendizagem sejam apresentadas, confrontadas entre si e, evidentemente, colocadas em debate, pode-se dizer que todas elas convergem (ou ao menos elas se propõem) para um mesmo objetivo: desenvolver uma educação de qualidade. Os procedimentos metodológicos e didáticos que se manifestam nas aulas de qualquer uma das disciplinas escolares, desse modo, são, sem dúvida, de extrema importância para a construção do sistema educacional e, por isso, sempre requerem maiores discussões e envolvimento da comunidade escolar por meio da dialogicidade.

Nos debates, pontuaram-se a gama de trabalhos que se referem aos meios de como desenvolver, do melhor jeito, uma aula. A partir daí pode-se perceber que são inúmeros os passos, recursos e estratégias que compõem as metodologias no campo da educação. Entretanto, Meurer (2010) acrescenta que, muitas vezes, os problemas educacionais não estão relacionados somente as metodologias didáticas adotadas, mas sim porque, 
A escola tornou-se distante da sociedade. Os muros a separam do cotidiano das vidas dos educandos, pais, comunidade. A comunidade na qual a escola encontra-se inserida, no campo, com possibilidades e saberes acumulados por agricultores e agricultoras, aparenta estar desconectada dos conhecimentos apresentados pelos educadores, destoando da comunidade, dos ritmos, ritos e cultura. A conhecimentos historicamente acumulados. (MEURER, 2010, p. 14-15).

Considerar todas metodologias que se apresentam nos planejamentos escolares da Geografia é fundamental. Certamente, as mesmas são um dos pilares principais para se pensar acerca do desenhar de uma aula diante do ensino remoto, mas são importantes para trazer o sentimento de familiaridade aos alunos. Elas se tornam relevantes na medida em que o professor precisa ter uma noção de como trabalhar os conteúdos de sua disciplina, no que se trata de tempo, materiais para desenvolvê-los e, essencialmente, de como abordá-los junto aos educandos em ambiente virtual, um desafio nesse período, pois precisa-se pensar, também, como abordar as vivências cotidiana dos mesmos no contexto atual.

Destaca-se que todo planejamento que se dá através das metodologias de ensino, do mesmo modo, por parte do professor na elaboração de seu plano de aula, por exemplo, é caracterizado pelas dúvidas. Esses assuntos foram pontuados em “Tópicos Especiais em Geografia B”, gerando reflexões aprofundadas sobre a escola das metodologias de ensino, sobre a excepcionalidade do contexto atual e, principalmente, sobre a necessidade de ver a escola para além da mera execução técnica de planos e sequências de aula. É central ver a escola em toda sua complexidade para, então, pensa como, por que e para quem ensinar. Esses questionamentos se intensificaram no período pandêmico com o ensino remoto, pois não se pode mais acompanhar de maneira presencial aos alunos.

Destaca-se que cada escola possui as suas singularidades e cada aluno, assim como cada educador, carregam suas experiências, alegrias, angústias, os seus pontos fortes e outros mais vulneráveis, sem pontuar, especificamente os contextos econômicos de cada instituição e de cada sujeito pertencente a comunidade escolar. Assim, por mais perfeita e/ou atrativa que certas metodologias parecessem, elas tiveram que ser reorganizadas agora e pode-se dizer que efetivamente não garantirão o mesmo sucesso das aulas presenciais.

Para tanto, é importante compreendermos que “[...] não teríamos como criar um modelo-gabarito-padrão de aula a ser seguida; mais do que isso, somo por natureza órfãos de um protótipo perfeito de como o aluno aprende e o professor, logo, deve ensinar." (BATISTA, 2019, p. 04). Portanto, deve-se levar em conta que um planejamento de ensino que proporcione resultados satisfatórios em uma turma pode ser que não atenda as mesmas expectativas de outra (BATISTA, 2019); afinal, são outros alunos - indivíduos - que internalizam e interagem sob um dado conteúdo de maneiras diferentes, em situações e espaços díspares. Sendo assim, não existe uma metodologia de ensino que seja como uma fórmula única, infalível e/ou indiscutível, que acarrete o êxito escolar, mas sim em inúmeras possibilidades diante de um campo educacional bastante complexo nesse cenário pandêmico. 


\section{CONCLUSÃO}

Todos os momentos de compartilhamento de ideias, de experiências e de saberes proporcionados pela disciplina “Tópicos Especiais de Geografia B”, ofertada pelo PPGGEO, da UFSM, favoreceram as reflexões sobre o ensino de Geografia, a formação de professores e o currículo escolar no contexto pandêmico. Os debates foram de suma importância para a formação continuada dos profissionais vinculados a pós-graduação e, também, para mudanças de cunho pessoais e para o aprofundamento dos debates acerca da realidade da educação no Cone Sul.

A disciplina foi, também, um espaço relevante para a construção de uma argumentação coerente acerca de um ensino de Geografia mais significativo e de qualidade, capaz de pautar não somente as metodologias de ensino, mas para compreender toda a complexidade de uma aula de geografia, bem como para fortalecimento dos debates sobre o ensino de Geografia, a formação docente e os currículos mesmo em tempos de o ensino remoto. Embora com algumas limitações proporcionadas pela pandemia, os alunos da Pós- graduação conseguiram driblá-las.

Em vista disso, chegou-se à conclusão de que ser professor(a) exige, entre muitas outras coisas, reinventar-se, refletir constantemente a respeito de suas práticas pedagógicas, avaliar a postura que adota diante das várias adversidades e oportunidades encontradas na profissão. Portanto, a presente disciplina foi um exemplo muito claro disso e potencializou a aprendizagem de todos os envolvidos na proposta.

\section{AGRADECIMENTOS}

O presente trabalho foi realizado com apoio da Coordenação de Aperfeiçoamento de Pessoal de Nível Superior - Brasil (CAPES) - Programa Nacional de Pós-Doutorado (PNPD - CAPES).

\section{REFERÊNCIAS}

BATISTA, N. L. Tópicos Especiais em Geografia B: Docência geográfica em tempos de pandemia. Metodologias e Aprendizado, v. 3, p. 167 - 175, 26 jul. 2020.

BATISTA, B. N. Como dar uma aula de geografia? Geografia Ensino \& Pesquisa: Santa Maria, v. 23, 2019 .

BATISTA, N. L.; LENZ, A. C.; DE DAVID, C. Formação de professores de Geografia no Brasil: relatos sobre a organização do IV Ciclo de Palestras go Grupo de Pesquisa em Educação e Território. Disciplinarum Scientia, Série: Ciências Humanas, Santa Maria, v. 21, n. 1, p. 11-23, 2020. 
EMENTA. Tópicos Especiais em Geografia B (GCC896). Santa Maria: PPGGeo/UFSM, 2020.

FREIRE, P. Educação como prática da liberdade. 30.ed. Rio de Janeiro: Paz e Terra, 2007.

MEURER, A. C. Projeto Político Pedagógico Escolar: questões a serem refletidas nas escolas do campo. In: MATOS, K. S. A. L.; WIZNIEWSKU, C. R. F. (Orgs.). Experiências e Diálogos em Educação do Campo. Fortaleza: Edições UFC, 2010. 
